\title{
ABASTECIMENTO DE ÁGUA NA CIDADE DE CAETITÉ ENTRE 2012 E 2016: INFLUÊNCIA DE ASPECTOS NATURAIS E IMPLANTAÇÃO DA ADUTORA DO ALGODÃO
}

\section{Water supply in the city of Caetité between 2012 and 2016: influence of natural aspects and implementation of the cotton adductor}

\section{Abastecimiento de agua en la ciudad de Caetité entre 2012 y 2016: influencia de aspectos naturales e implantación de la adducora del algodón}

\author{
Vagner Santos Dantas de Almeida ${ }^{1}$ https://orcid.org/0000-0003-4069-6084 \\ Manoel Alves de Oliveira ${ }^{2}$ https://orcid.org/0000-0001-5220-2593.
}

\footnotetext{
${ }^{1}$ Graduando em Geografia pela Universidade do Estado da Bahia-UNEB, Campus VI, e-mail: vagnerdantas91f@gmail.com.

${ }^{2}$ Doutor em Geografia pela UFF. Professor adjunto do curso de Licenciatura em Geografia da Universidade do Estado da BahiaUNEB, Campus VI, Caetité-BA. Coordenador do Grupo de Pesquisa Geografia e transformações contemporâneas e-mail: mano.geografia@gmail.com.
}

Recebido em: 31-01- 2019

\section{Resumo}

A distribuição da água pela superfície do Planeta Terra não ocorre de forma homogênea, ocasionando a existência de regiões que sofrem com o déficit hídrico, em especial a porção referente à água doce, o que impulsiona o emprego de ações para gestão desse elemento natural. Este artigo apresenta os resultados de uma pesquisa que teve como objetivo analisar a situação do abastecimento hídrico da cidade de CaetitéBahia a partir da implantação da Adutora do Algodão entre os anos de 2012 e 2016, diante do descompasso da distribuição da água no município que integra o semiárido nordestino.

Palavras-chave: Aspectos fisiográficos. Abastecimento Hídrico. Adutora do Algodão.

\begin{abstract}
The distribution of water on the surface of Planet Earth does not occur homogeneously, causing the existence of regions suffering from water deficit, especially the portion related to fresh water, which drives the use of actions to manage this natural element. This article presents the results of a research that had as objective to analyze the water supply situation of the city of Caetité-Bahia from the implantation of the Cotton Adductor between the years of 2012 and 2016, due to the mismatch of water distribution in the municipality that integrates the Northeastern semiarid.
\end{abstract}

Keywords: Physiographic aspects. Water Supply. Cotton Adductor.. 


\section{Resumen}

La distribución del agua por la superficie del Planeta Tierra no ocurre de forma homogénea, ocasionando la existencia de regiones que sufren con el déficit hídrico, en especial la porción referente al agua dulce, lo que impulsa el empleo de acciones para la gestión de ese elemento natural. Este artículo presenta los resultados de una investigación que tuvo como objetivo analizar la situación del abastecimiento hídrico de la ciudad de Caetité-Bahía a partir de la implantación de la Adducora del Algodón entre los años 2012 y 2016, ante el descompuesto de la distribución del agua en el municipio que que integra el semiárido nordestino.

Palabras clave: Aspectos fisiográficos. Abastecimiento Hídrico. Adductor del Algodón.

\section{Introdução}

A água é um elemento de fundamental importância para manutenção da vida. Impulsionado pela energia solar, esse recurso encontra-se presente nas mais variadas regiões do Planeta. Porém, é irregularmente distribuída o que condiciona cenários de aridez e semiaridez em diversas localidades continentais, tornando um desafio para algumas comunidades que tentam se manter sob condições de escassez por vezes severas e, nesses casos, demandando intervenções do poder público para promover meios de convivência com a seca.

Diante dessa premissa, entende-se que por estar localizado no Centro Sul da Bahia, partilhando das peculiaridades do semiárido nordestino, e sendo a cidade um âmbito de (re)produção do espaço geográfico é que a investigação parte da hipótese de que a ampliação da demanda por abastecimento de água potável em Caetité e as fisionomias naturais do município foram fatores determinantes na instalação da Adutora do Algodão.

Sobre essa ótica, a presente pesquisa visa analisar o sistema de abastecimento de água da cidade de Caetité entre 2012 e 2016, contextualizando-o com as fisionomias naturais do município e com a implantação da Adutora do Algodão. Em consonância aos desígnios da pesquisa faz-se inerente o conhecimento do quadro atual da disponibilidade hídrica de Caetité, refletir sobre o perfil hidrogeológico do município e inferir sobre a importância da estação da Adutora para a respectiva cidade.

A metodologia adotada para o desenvolvimento da pesquisa partiu do embasamento teórico, através de consultas bibliográficas e documentais, seguida de abordagens empíricas para o levantamento de informações, no ponto de captação das águas do Rio São Francisco e Estação de Tratamento de Água da Adutora do Algodão, entrevistas aos funcionários dos departamentos responsáveis pela gestão dos recursos hídricos na cidade de Caetité e aos moradores locais. 
No artigo, também estão presentes produtos cartográficos e dados meteorológicos, organizados através de bancos dados de órgãos públicos, para a verificação das peculiaridades naturais da sede do município de Caetité.

Para estruturação da pesquisa, foi realizada inicialmente a seleção de referenciais bibliográficos, que abordam as peculiaridades dos recursos hídricos e os aspectos naturais que influem na distribuição da água sobre a superfície do Planeta Terra. A pesquisa também possui um cunho documental na qual foram examinadas as Leis $n^{\circ} 9.443$, de 08 de janeiro de 1997 (Política Nacional de Recursos Hídricos), a Lei n 11.445, de 05 de janeiro de 2007 (diretrizes nacionais para o saneamento básico) e a Lei $n^{\circ} .632$ de 10 de outubro de 2006 (Plano de Desenvolvimento do Município de Caetité).

Após o embasamento teórico empreendeu-se visitas a departamentos incumbidos de gerenciar e físcalizar o uso dos recursos hídricos no município, como a Secretaria de Recursos Hídricos de Caetité e a Unidade Regional da Empresa Baiana de Águas e Saneamento S.A. (EMBASA) nesta cidade, para a coleta de informações via entrevista. A visita a área de captação e tratamento da Adutora do Algodão, em outubro de 2015, também foi essencial para a pesquisa, possibilitando o conhecimento das etapas iniciais do sistema adutor.

Realizaram-se consultas a moradores da cidade de Caetité quanto ao abastecimento hídrico da cidade. Para a coleta dos dados, recursos como gravador de voz e bloco de notas foram essenciais para registrar toda a ação durante as entrevistas. Para garantir a percepção panorâmica da situação do abastecimento de água na cidade, as entrevistas ocorreram com moradores de diferentes bairros. E, por não dispor de um ofício que autorize a divulgação do nome dos moradores, a identificação dos mesmos foi substituída por "Morador" seguido de uma letra em ordem alfabética.

Operou-se também na organização de dados meteorológicos do INMET, referentes à estação convencional de Caetité, para análise da dinâmica atmosférica da cidade. Além do uso de bases cartográficas do IBGE, Companhia de Pesquisa de Recursos Minerais (CPRM), Unidade Regional da Embasa de Caetité (UREC), do Sistema Eletrônico de Informações (SEI) e do grupo de estudos GEO VI para as produções cartográficas ${ }^{3}$.

Em gabinete, além da preparação da base teórica-metodológica, atuou na análise dos dados das observações in loco, bem como na redação final da pesquisa. Espera-se também

\footnotetext{
${ }^{3}$ As produções cartográficas foram realizadas através dos softwares Quantum GIS 2.18.7 (2017), disponível em $<$ https://www.qgis.org/en/site/>, e do Google Earth Pro (2017), disponível em <https://www.google.com/earth/download/gep/agree.html>.

V. 3, n. 1, 2019 http://periodicos2.uesb.br/index.php/geo
}

Este é um artigo de acesso aberto sob a licença Creative Commons da CC BY 
que o presente trabalho possa auxiliar outros pesquisadores que necessitem de fontes de dados e referenciais relacionadas à temática aqui abordada.

\section{O abastecimento de água na cidade de Caetité: Disponibilidade hídrica: adversidades}

\section{físico-naturais}

A sede do município de Caetité está localizada na Mesorregião Centro-Sul Baiana e Microrregião de Guanambi, também conhecido como Território de Identidade do Sertão Produtivo (IBGE, 2013).

A sede de Caetité situa-se na Serra Geral ou Planalto do Espinhaço a uma altitude de $825 \mathrm{~m}$. Por estabelecer no vale final da Serra, sentido sul-norte, os relevos da cidade são bastante elevados. É caracterizada por estar arquitetada na transição do cerrado - denominado localmente de "Gerais" - para caatinga, ou cerrado-floresta decidual, com clima Semiárido e subúmido a seco (CAETITÉ, 2016).

Segundo o último Censo Demográfico do Instituto Brasileiro de Geografia e Estatísticas (IBGE) de 2010, o município comporta um contingente populacional de 47.515 habitantes, cuja 28.456 desse total vivem na Zona Urbana e 19.068 na Zona Rural (IBGE, 2016).

Mapa 01 - Caetité nos períodos de estiagem no semiárido nordestino

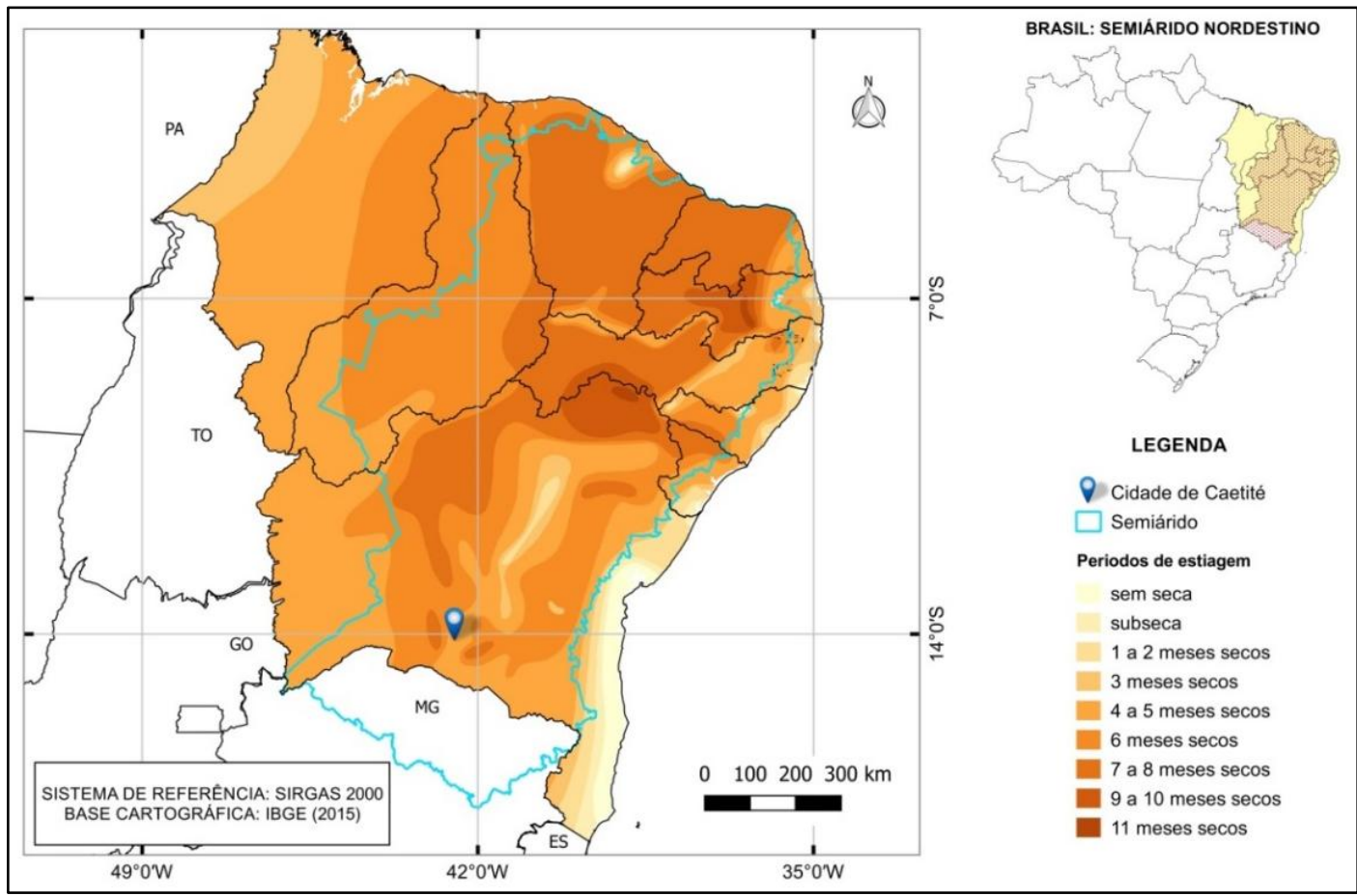

Fonte: IBGE (2015). Org. e elabo. por Almeida, V. S. D. (2017).

\section{3, n. 1, 2019 http://periodicos2.uesb.br/index.php/geo}

Este é um artigo de acesso aberto sob a licença Creative Commons da CC BY 
Inserida no Centro-Sul baiano, a cidade de Caetité partilha das peculiaridades do semiárido nordestino. Localizada na transição do Bioma Cerrado para o Bioma Caatinga, a vegetação que envolve a sede do município evidencia a ressonância desse cenário, um reflexo dos atributos atmosféricos instaurados nesse espaço geográfico, que, de acordo com $\mathrm{Ab}$ ' Saber (2003), são domínios caracterizados por longos períodos de estiagem e curtos intervalos, concentrados, de precipitação.

Apurando as informações do Mapa 1, pode-se constatar que Caetité está geograficamente posicionada em um local cujos fatores climáticos promovem de quatro a seis meses de secas, e assim, favorecendo altos índices de evapotranspiração, dificultando a manutenção dos mananciais locais e a diminuição do tempo de residência das águas nos reservatórios, seja por fatores naturais ou antrópicos.

Enfatizando as respectivas abordagens, os dados do Gráfico 1, da estação meteorológica de observação de superfície convencional (código Organização Meteorológica Mundial - OMM: 83339) da cidade de Caetité, apresenta um aspecto panorâmico e quantificado de algumas variáveis atmosféricas, como precipitação, evaporação e temperatura, entre aos anos de 1961 a 2016.

Gráfico 01 - Climograma de Caetité, período de 1961-2016

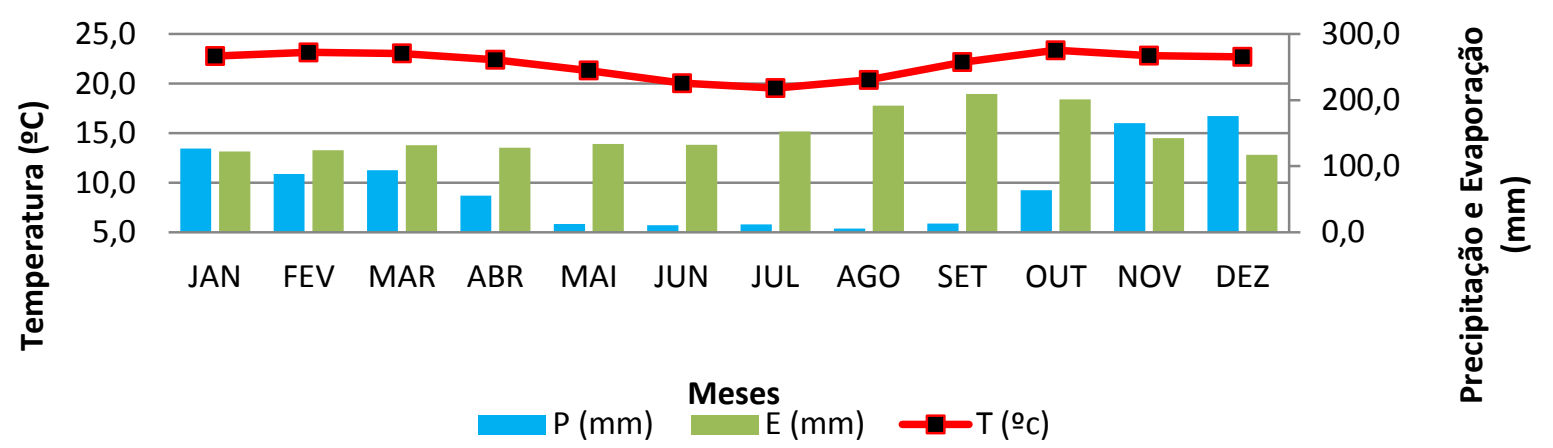

Fonte: INMET. Org. por Almeida, V. S. D. (2017).

Verificando o climograma do Gráfico 1 é possível constatar que a cidade de Caetité não possui uma distribuição anual regular de chuvas, estando o seu regime pluviométrico de maior volume concentrado de outubro a abril, proporcionando índices médios da ordem de $800 \mathrm{~mm}$ anualmente. Entretanto, os meses entre maio e setembro são os que apresentam os menores índices pluviométricos, pouco ultrapassando o 5,0 mm, dado ao fato de que as faixas 
de nebulosidade das Zonas de Convergência encontram condições atmosféricas propicias para atuação durante o verão.

O climograma do Gráfico 1 também evidencia um cenário caracterizado pela insuficiência hídrica, haja vista que, de acordo com Rebouças (2006), quando a quantidade de água precipitada é menor que à evaporada, cujo valor corresponde a um resultado negativo, diz-se que há um "déficit hídrico". Porém, durante a ocorrência do fenômeno El Niño a discrepância entre os valores da precipitação e evaporação são ainda mais proeminentes.

A disponibilidade de água no respectivo espaço geográfico é também limitada pela baixa capacidade geológica para formação de reservas hídricas, já que a cidade de Caetité, segundo o Radambrasil (1982), está estruturada sobre um embasamento litológico de rochas metassedimentares/metavulcânicas, relacionada ao aquífero do tipo fissural.

O embasamento litológico relacionado aos metassedimentos/metavulcânicos, conforme a CPRM (2006), é caracterizado por porosidade secundária representada por fraturas e fendas, com reservatórios aleatórios, descontínuos e de pequena extensão.

Esse processo de armazenamento é lento, fazendo com que o solo absorva pouca água em um curto período de espaço-tempo e com isso impossibilitando uma rápida manutenção das reservas subterrâneas frente às necessidades da crescente demanda local, seja em uso doméstico ou comercial.

Diante disso, mesmo a cidade de Caetité sendo contemplada com uma média de 800 $\mathrm{mm}$ de chuvas, ela não disponibiliza de mecanismo naturais para o armazenamento de grandes volumes de água em comparação a multiplicidade dos usos a que o recurso hídrico é destinado.

\section{Normatizações técnicas e contratuais}

O abastecimento de água constitui um dos serviços do saneamento básico disposto na Lei Federal 11.445/2007, que estabelece a garantia de potabilidade desse recurso, acessibilidade e segurabilidade a uma população local. A mesma Lei também determina no artigo $9^{\circ}$ que o serviço para o saneamento é de competência dos seus titulares e, neste caso, recai sobre os municípios parte da responsabilidade no planejamento desse conjunto de atividades públicas.

O Plano de Desenvolvimento do Munícipio de Caetité (PDM), também ressalta que: 
A Municipalidade, nos termos da Constituição Federal, detém o direito sobre os serviços de água e esgotamento sanitário em todo o território do Município, em regime de monopólio podendo exercer tal direito diretamente, ou através de terceiros mediante concessão do direito de exploração [...], por prazo e condições predeterminados [...] (LEI No . 632/2006, Art. 134 $\left.{ }^{\circ}\right)^{4}$.

Sobre essa ótica, mediante o artigo 241 da Constituição Federal de 1988 que flexibiliza o encargo dos titulares na prestação do saneamento básico, o Município de Caetité externalizou seus serviços com a celebração de contrato de Concessão com a EMBASA em 02 de junho de 1972. Mesmo após o vencimento do contrato, em 02 de junho de 1992, a estatal permaneceu fornecendo seus serviços até a sua renovação, por Convênio de Cooperação, em 31 de maio de 2011, autorizado pela Lei municipal $\mathrm{n}^{\circ}$ 723. A Prefeitura de Caetité também consente com a atuação, para regulação e fiscalização, da Agência Reguladora de Saneamento Básico do Estado da Bahia (AGERSA) (AGERSA, 2014).

Diante disso, conforme o PDM de Caetité (2006), fica a cargo da Prefeitura de Caetité a coordenação dos "Sistemas de Abastecimento de Água das Comunidades Rurais", promovendo toda assistência técnica em infraestrutura e operacionalização às associações de usuários.

\section{Suplementação hídrica: a implantação da adutora do algodão na cidade de Caetité}

Desde 2009, Caetité vem registrando desvios pluviométricos (dias não consecutivos de chuvas) da média anual padrão, o que têm comprometido a manutenção das reservas hidrogeológicas e consequentemente diminuindo a sua disponibilidade de água para o abastecimento da cidade, conforme dispostos no Quadro 1.

Esse longo período de déficit pluviométrico decorre, segundo a climatologista Renata

Tedeschi do Centro de Previsão de Tempo e Estudos Climáticos (CPTEC), em entrevista a UOL (2017), da combinação infeliz de alguns de fatores, como o aquecimento anômalo da superfície do mar do Atlântico Norte e a ocorrência do fenômeno El Niño.

A ocorrência dessas anomalias positivas exerce forte influência na atuação da Zona de Convergência Intertropical (ZCIT) e na Zona de Convergência do Atlântico Sul (ZCAS), repercutindo na insuficiência de chuvas em quase toda extensão do Nordeste, principalmente no semiárido, isso porque ambos os sistemas meteorológicos são responsáveis pela manutenção do regime pluviométrico da região.

\footnotetext{
${ }^{4}$ Texto extraído da página Câmara Municipal de Caetité, secção documentos, disponível: http://www.camaracaetite.ba.gov.br/site/wp-content/uploads/2015/11/plano-de-desenvolvimento-municipal.pdf

V. 3, n. 1, 2019 http://periodicos2.uesb.br/index.php/geo
}

Este é um artigo de acesso aberto sob a licença Creative Commons da CC BY 
Quadro 01 - Acúmulo pluviométrico mensal da cidade de Caetité em mm (2009-2016)

\begin{tabular}{|c|c|c|c|c|c|c|c|c|}
\hline MESES & $\mathbf{2 0 0 9}$ & $\mathbf{2 0 1 0}$ & $\mathbf{2 0 1 1}$ & $\mathbf{2 0 1 2}$ & $\mathbf{2 0 1 3}$ & $\mathbf{2 0 1 4}$ & $\mathbf{2 0 1 5}$ & $\mathbf{2 0 1 6}$ \\
\hline JAN & $\mathbf{5 4 , 3}$ & 15,1 & 27,7 & 51,4 & 202,6 & 10,2 & 1,6 & 401 \\
\hline FEV & 43,4 & 17,4 & 139,1 & 53,2 & 0 & 32,6 & 107 & 14 \\
\hline MAR & 185,1 & 213,4 & 129,1 & 11,9 & 87,3 & 39,6 & 42,6 & 0 \\
\hline ABR & 80,9 & 50,4 & 43,8 & 0 & 7,2 & 29,4 & 97,6 & 0,6 \\
\hline MAI & 4,6 & 16,6 & 6,8 & 11,6 & $\mathbf{7 , 4}$ & 14,2 & 34,3 & 0,2 \\
\hline JUN & 10,6 & 1,5 & 0,4 & 10,5 & 8 & 18,6 & 3,6 & 10,9 \\
\hline JUL & 17,3 & 18,4 & 17,2 & 12,1 & 11,8 & 9,7 & 13,3 & 5,3 \\
\hline AGO & 1,2 & 6 & 1,2 & 12,7 & 5,4 & 1 & 9,2 & 5,3 \\
\hline SET & 13,6 & 0 & 0 & 3 & 9,1 & 1 & 0 & 3,6 \\
\hline OUT & 209,7 & 71,6 & 48 & 0,4 & 30,1 & 63,6 & 15,2 & 7,7 \\
\hline NOV & 44,8 & 146,7 & 119 & 454,9 & 73,3 & 158,7 & $\mathbf{7 2 , 6}$ & 209,4 \\
\hline DEZ & 175,3 & 142 & 233,4 & 45,9 & 292,5 & 182,4 & 26,2 & 63,4 \\
\hline \hline TOTAL ANUAL & $\mathbf{8 4 0 , 8}$ & $\mathbf{6 9 9 , 1}$ & $\mathbf{7 6 5 , 7}$ & $\mathbf{6 6 7 , 6}$ & $\mathbf{7 3 4 , 7}$ & $\mathbf{5 6 1}$ & $\mathbf{4 2 3 , 2}$ & $\mathbf{7 2 1 , 4}$ \\
\hline
\end{tabular}

Fonte: INMET. Org. por Almeida, V. S. D. (2017).

Diante das configurações naturais adversas o abastecimento urbano de água em Caetité tem o seu quantitativo comprometido devido ao baixo volume dos mananciais, acometidos pela inexpressividade das ordens pluviométricas.

Em conformidade com o artigo 23 inciso XI e o artigo 46 da Lei 11.445/07 a Unidade Regional da Embasa de Caetité (UREC), em 2012, adota, como mecanismo de contingência, o racionamento hídrico. Essa medida de caráter emergencial e preventiva consistiu em regulamentar a liberação hídrica com intervalos de quatro dias para o abastecimento das residências.

Esse mecanismo de provisão hídrica intermitente afetou a rotina diária dos moradores, que segundo estes, tiveram que aumentar o potencial residencial dos reservatórios de água, seja com a aquisição de novas caixas d'água ou baldes com capacidade média de 50 litros, além de garrafas pets e outros recipientes, tudo para compensar os quatro dias de racionamento. Até as atividades domésticas básicas, como "faxina" e a "lavagem de roupas", e que exigem consideráveis volumes desse recurso, tiveram de ser realizadas no decorrer dos dias de abastecimento, já que durante o racionamento as prioridades eram a higiene pessoal, preparação de alimentos e ingestão.

Alguns moradores também manifestaram aversão quanto ao cumprimento do cronograma estabelecido pela UREC, devido ao prolongamento dos dias de racionamento, com as residências chegando a uma semana inteira sem abastecimento. 
Por não dispor de uma rede de distribuição hídrica independente alguns serviços públicos acabaram submetidos ao racionamento, como as instituições de ensino, que tiveram de reorganizar a grade de horários para reduzir o tempo das aulas durante esse período, e a Unidade de Pronto Atendimento 24 horas (UPA), que, segundo alguns moradores, limitaram a realização de alguns atendimentos, gerando transtornos por parte dos pacientes. Mas conforme o Secretário de Recursos Hídrico de Caetité a UREC sempre manteve a disposição um caminhão pipa para o abastecimento dessas entidades, para garantir o funcionamento das mesmas durante os dias de racionamento.

A tônica do déficit hídrico na cidade ocasionou a interrupção até da execução de obras prediais, assim como a impossibilidade da ocupação de novas edificações, principalmente nas áreas periféricas. Segundo a UREC, a conjuntura em questão inviabilizava o aumento da alocação de água para alimentação de novos hidrômetros, principalmente pelas prioridades sumariamente definidas, como a conservação dos mananciais e a garantia do fornecimento hídrico as unidades usuárias já consolidadas.

O controle do uso da água através do racionamento, apesar de promover um cenário relativamente conturbado, foi a alternativa com melhor viabilidade adotada pela concessionária, sendo a inexpressividade das reservas naturais e a inexistência de uma artificial os fatores cruciais para a adoção da respectiva medida.

O mecanismo de contingência visava disciplinar os usos da água em épocas de pouca oferta e muita demanda e dirimir eventuais conflitos, além de assegura a (re)produção do espaço urbano de Caetité.

\section{A situação atual do abastecimento de água na cidade de Caetité}

A escala de manobra adotada pela UREC promoveu a oferta de água para todos os usuários da zona urbana de Caetité durante os longos períodos de estiagem. Contudo, por ser volátil, essa medida emergencial não garante viabilidade a longo prazo, demandando mecanismos com maior estabilidade temporal, já que não existe um prognóstico de condições meteorológicas favoráveis. Para equalizar a disponibilidade desse recurso na sede do município, a transposição entre bacias hidrográficas, apresenta-se como um procedimento técnico que melhor se adequa à realidade em questão.

Com o propósito de elevar a oferta hídrica, a Adutora do Algodão, obra integrante ao Programa de Aceleração do Crescimento (PAC) 2 e em funcionamento desde 2012, fornece 
água potável para mais de 165 mil residências. O projeto, que totalizou $\mathrm{R} \$ 180$ milhões, é o resultado de um convênio de cooperação técnica entre a CODEVASF, vinculada ao Ministério da Integração Nacional, e o governo da Bahia, por meio da EMBASA, com a finalidade de alocar as águas do rio São Francisco para o beneficiamento hídrico de nove Municípios integrantes do semiárido nordestino, dentre os quais encontra-se Caetité (CODEVASF, 2017).

O sistema de adução da Adutora do Algodão ocorre em três etapas, atendendo a sedes de municípios, localidades distritais e outras comunidades localizadas na zona de influência. A primeira abrange municípios que compõem a própria bacia hidrográfica do Rio São Francisco, como Guanambi, Candiba, Iuiú, Malhada, Matina, Palmas de Monte Alto e Pindaí. Na segunda e terceira etapa, a transposição de águas, por meio de estações elevatórias, ocorre entre a bacia do São Francisco e a sub-bacia receptora do Rio de Contas pertencente à Região Hidrográfica do Atlântico Leste, beneficiando os Municípios de Caetité, Lagoa Real, Rio do Antônio.

Ao entrar em operação total no terceiro trimestre de 2016 a segunda etapa do Sistema Integrado de Abastecimento de Água (SIAA) da Adutora do Algodão elevou a oferta hídrica da cidade de Caetité, promovendo o fim do racionamento, com uma vazão entre 75,91 e 78,0 litro por segundo (1/s), correspondendo a uma oferta para consumo de cerca de 170 1/hab./dia, o que supera a média nacional de 160 litros.

No entanto, pôde-se perceber através da aquisição de informações com alguns moradores locais de diferentes bairros, quando perguntados sobre a atual situação do abastecimento, que o fornecimento de água apresenta uma frequência nas imediações próximas às redes primárias de distribuição, localizadas no interior da cidade, e oscilam, com intervalos de dois a quatro dias, em direção as áreas periféricas, mesmo após a implantação da Adutora do Algodão.

Mas, segundo a UREC, o processo de distribuição é realizado através de condutos forçados por gravidade a partir dos Reservatórios de Água Potável (RAP), não necessitando de uma estação de bombeamento, já que a topografia local permite a realização dessa ação mecânica e em caso de liberação de todo o sistema tubular a água não terá força para alcançar as edificações localizadas nos extremos da cidade, ocasionando a perda de pressão devido ao grande número de registros hidráulicos prediais em operação, o que torna necessário intercalar os dias de fornecimento hídrico entre as zonas de abastecimento para garantir a eficiência do processo. 
Nesse sentindo, o racionamento, adotado entre os anos de 2012 a 2015, configura-se como uma medida de contingência mediante a adversidades naturais que comprometeram o quantitativo hídrico nos mananciais, mas interrompida ou que chegou ao fim com a implantação da Adutora do Algodão. Já o abastecimento intermitente ou alternado em questão, que se mantém mesmo após o sistema adutor, é o resultado de uma estratégia técnica via a estruturação do Sistema Integrado de Abastecimento de Água (SIAA) da cidade.

Porém, vale ressaltar que o artigo 43 da Lei 11.445/2007 estabelece um fornecimento regular e contínuo de água potável. O abastecimento hídrico ininterrupto é uma das condições essenciais para o bem-estar dos consumidores, por favorecer a manutenção da salubridade das edificações e dos afazeres necessários para a conservação da vida.

Nesse sentido, o aperfeiçoamento da infraestrutura do sistema de abastecimento pela UREC é indispensável para a melhora da frequência com que a água potável chega ao consumidor final, como, por exemplo, a construção de novos RAP nas áreas da cidade com o provimento hídrico volátil. Pode-se até prezar por um fornecimento sistemático, mas que este ocorra intercalado no máximo dentro de um período de 24 horas.

A vazão de alocação de água da Adutora do Algodão, conforme apresentado, correspondente à ordem de 170 1/hab./dia o que eleva a capacidade operacional da UREC e possivelmente viabiliza a estruturação da respectiva ação.

Assim, diante do exposto, entende-se que a ampliação das obras da Adutora do Algodão até a sede do município de Caetité tem como objetivo atender à população para promover um equilíbrio entre a oferta e a demanda, além de suprimir eventuais possibilidades de conflitos, decorrente das constantes reclamações dos habitantes submetidos ao racionamento e atenuar os efeitos da estiagem prolongada.

\section{Considerações finais}

A pesquisa objetivou-se a analisar o sistema de abastecimento de água na cidade de Caetité, contextualizando-o com as fisionomias naturais do município e com a instalação da Adutora do Algodão. Para esse fim, foi necessário o levantamento de informações acerca da temática em estudo, provenientes de referenciais bibliográficos, bases cartográficas e dados meteorológicos.

O êxito para com os objetivos propostos mostrou-se satisfatório, pois foi possível: 
- Conhecer o quadro atual da disponibilidade hídrica da cidade de Caetité: evidenciando a influência da ocorrência das anomalias positivas, como o El Nino e o aquecimento das águas do Atlântico Norte, no deslocamento dos sistemas meteorológicos, responsáveis pelas linhas de instabilidade que chegam ao município, que, desde 2010, vem intensificando os períodos de estiagem e influenciando nos baixos volumes pluviométricos anuais.

- Refletir sobre o perfil hidrogeológico do município de Caetité: o estudo sobre a estrutura desse embasamento litológico foi essencial para compreender o quanto à manutenção dessa reserva pode ser afetada pelos baixos índices pluviométricos. A base cartográfica da CPRM e o Radambrasil atestaram um aquífero do tipo fissural, relacionado aos metassedimentos/metavulcânicos, caracterizado por um armazenamento lento.

- Inferir sobre a importância da estação da Adutora do Algodão para a sede do município de Caetité: diante dos aspectos naturais apresentados torna-se evidente a vulnerabilidade do quantitativo hídrico na cidade de Caetité. $\mathrm{O}$ atendimento a demanda e os riscos de supressão das reservas hidrogeológicas tonaram-se um entreve para operacionalização do SIAA pela UREC. A implantação do sistema adutor possibilitou a melhora no abastecimento hídrico da cidade, além de amenizar as reclamações populacionais decorrente do racionamento ocorrido de 2012-2015. No entanto ainda vigora um abastecimento intermitente, ocasionada pela falta de eficiência no fornecimento dos serviços de saneamento.

Contemplando positivamente os objetivos, pode-se aferir a veracidade da conjectura apresentada. No entanto, os aspectos naturais mostraram-se como o fator condicionante de maior proeminência na instalação do SIAA da Adutora do Algodão em relação ao crescimento da demanda, por repercutir no desvio anual de precipitação abaixo da média padrão, dificultando a manutenção dos mananciais de água utilizados para o abastecimento da população da cidade de Caetité.

Durante a realização empírica alguns infortúnios permearam no percurso, mas, não inviabiliza os resultados obtidos. Como a falta de respostas das Secretárias Municipais de Caetité de Recursos Hídricos, do Meio Ambiente e Infraestrutura e da UREC sobre a elaboração do Plano Municipal de Saneamento Básico (PMSB), um processo improdutivo e exaustivo devido à burocracia e negligência por parte dos departamentos. Nota-se também uma aparente negligência por parte da prefeitura acerca do quadro de saneamento da cidade 
de Caetité, a pesar das diretrizes contratuais a administração pública do município não deveria se isentar completamente dessa questão.

No entanto, o processo investigativo da pesquisa impulsionou a repercussão de algumas questões no cognitivo, que estão diretamente relacionadas com a temática em pauta, como:

- a importância de uma gestão hidrogeológica do município de Caetité, haja vista que essa é uma das principais fontes de água para o abastecimento da população, urbana e rural;

- a eficiência na prestação dos serviços de saneamento da UREC;

- a importância do Plano Municipal de Saneamento Básico (PMSB) para o município de Caetité na promoção de um ambiente salubre;

- a vulnerabilidade hídrica de municípios do Sertão Produtivo Baiano e o potencial aumento da oferta de água pelo SIAA da Adutora do Algodão.

Mesmo atingindo os objetivos pretendidos, a pesquisa permeia um eixo central, o Sistema Integrado de Abastecimento de Água, que tenciona propostas para a realização de trabalho futuros, que em formações continuadas, poderão abranger comunidades integrantes do Sertão Produtivo Baiano.

\section{Referências}

AGERSA. Relatório de fiscalização: sistemas de abastecimento de água e de esgotamento sanitário do município de Caetité. AGERSA: dezembro, 2014. PDF.

Câmara municipal de Caetité. Plano de desenvolvimento do munícipio de Caetité: lei $\mathrm{n}^{\circ}$. 632 de 10 de outubro de 2006. Disponível em: <http://www.camaracaetite.ba.gov.br/site/wpcontent/uploads/2015/11/plano-de-desenvolvimento-municipal.pdf $>$. Acesso em: 16 de novembro de 2016.

CODEVASF. Adutora do Algodão entra em operação e termina racionamento de água em Guanambi. Disponível em: <http://www.codevasf.gov.br/noticias/2007/adutora-doalgodao-entra-em-operacao-e-termina-racionamento-de-agua-em-guanambi/>. Acesso em: 01 de dezembro 2016.

CPRM. Mapa de domínios/subdomínios hidrogeológicos do Brasil em ambiente SIG: concepção e metodologia. Disponível em: <http://www.cprm.gov.br/publique/media/evento_PAP002766.pdf >. Acesso em: 25 de abril de 2017.

EMBASA. Relatório anual de informação ao consumidor 2015: sistema de abastecimento de água do município de Caetité. Bahia Governo do Estado: EMBASA, 2015. 
HELLER, Léo. Abastecimento de água, sociedade e ambiente. In: HELLER, Léo; PÁDUA, Valter Lúcio de. Abastecimento de água para consumo humano. 2. ed. rev. e atual.- Belo Horizonte: Editora UFMG, 2010. 1 v.: il. - (Ingenium). p. 29-64.

IBGE. Caetité. Disponível em: <http://cidades.ibge.gov.br/xtras/perfil.php?codmun=290520 $>$. Acesso em: 01 de março de 2016.

IBGE. Biblioteca: Projeto Radambrasil - Brasília, Área da Folha SD. 23; Recursos naturais. Disponível em: <http://biblioteca.ibge.gov.br/visualizacao/livros/liv14552.pdf>. Acesso em: 29 de maio de 2017.

INMET. Estações e dados: BDMEP - dados históricos. Disponível em: <http://www.inmet.gov.br/portal/index.php?r=bdmep/bdmep>. Acesso em: 10 de maio de 2017.

Morador A. Entrevista concedida a Vagner Santos Dantas de Almeida. Caetité-BA, julho de 2017. [A entrevista encontra-se transcrita no Apêndice "2" da monografia].

Morador B. Entrevista concedida a Vagner Santos Dantas de Almeida. Caetité-BA, julho de 2017. [A entrevista encontra-se transcrita no Apêndice "2" da monografia].

Morador D. Entrevista concedida a Vagner Santos Dantas de Almeida. Caetité-BA, agosto de 2017. [A entrevista encontra-se transcrita no Apêndice "2" da monografia].

REBOUÇAS, Aldo da C. Água doce no mundo e no Brasil. In: REBOUÇAS, Aldo da C; BRAGA, Benedito; TUNDIZI, José Galizia. Águas doces no Brasil: capital ecológico, uso e conservação. $3^{\circ}$ ed. São Paulo: Escrituras Editora, 2006. p. 01-35.

UOL. Por que chove tanto no Nordeste, mas o sertão continua seco?. Disponível em: $<$ https://noticias.uol.com.br/ciencia/ultimas-noticias/redacao/2017/06/01/seca-e-chuva-aomesmo-tempo-entenda-os-climas-diferentes-do-nordeste.htm>. Acesso em: 19 de maio de 2017.

Sem ZCAS e sem ZCIT. Climatempo Meteorologia. Youtube. 27 de jan. de 2015. 2min37s. Disponível em: <https://www.youtube.com/watch?v=aQizVcAtugk>. Acesso em: 08 de setembro de 2017.

TUNDISI, José Galizia. Água no século XXI: enfrentando a escassez. 2. ed. São Carlos. RiMa, Instituto Internacional de Ecologia, 2005. 